National Marine

Fisheries Service

NOAA
Fishery Bulletin

ar established in 1881 \%
Spencer F. Baird

First U.S. Commissione

of Fisheries and founde of Fishery Bulletin
Abstract-Migratory behavior affects growth, survival, and fitness of individual fish, the dynamics and resilience of populations, and the ecosystems that fish occupy. Many salmonids are anadromous but individuals vary in the duration and spatial extent of marine migrations. We used telemetry to investigate movements of Chinook salmon (Oncorhynchus tshawytscha) that remained in Puget Sound (residents) rather than migrated to the Pacific Ocean. Most tagged Chinook salmon (26 of $37=70 \%$ ) remained in Puget Sound for a substantial period, staying in the region where captured. However, $30 \%$ of tagged individuals, termed "transients," subsequently left Puget Sound. Residents and transients did not differ in tagging date, body size, or origin (hatchery or wild). Compared with sympatric coho salmon (O. kisutch) where $80 \%$ remained as residents according to similar data, Chinook salmon tended to be detected closer to shore, in shallower water, and on fewer different receivers. For both species, residents showed limited movement within Puget Sound. We conclude that Chinook and coho salmon display resident and transient movement patterns across a behavioral continuum rather than within discrete migrational categories. These movement patterns are important because they affect the role of salmon in the ecosystem, their vulnerability to fisheries, and their accumulation of chemical contaminants.

Manuscript submitted 11 January 2017. Manuscript accepted 24 August 2017. Fish. Bull. 115:544-555 (2017).

Online publication date: 14 September 2017. doi: 10.7755/FB.115.4.10

The views and opinions expressed or implied in this article are those of the author (or authors) and do not necessarily reflect the position of the National Marine Fisheries Service, NOAA.

\title{
Residency, partial migration, and late egress of subadult Chinook salmon (Oncorhynchus tshawytscha) and coho salmon (O. kisutch) in Puget Sound, Washington
}

\author{
Anna N. Kagley (contact author)' \\ Joseph M. Smith² \\ Kurt L. Fresh ${ }^{1}$ \\ Kinsey E. Frick ${ }^{1}$ \\ Thomas P. Quinn² \\ Email address for contact author: anna.kagley@noaa.gov \\ 1 Northwest Fisheries Science Center \\ National Marine Fisheries Service, NOAA \\ 2725 Montlake Boulevard East \\ Seattle, Washington 98112 \\ 2 School of Aquatic and Fishery Sciences \\ University of Washington \\ Box 355020 \\ Seattle, Washington 98195
}

Many of the world's most abundant fish species are migratory within fresh or marine waters or between these distinct environments (Lucas and Baras, 2001; Secor, 2015). However, species and populations often vary greatly in the prevalence, duration, and spatial extent of their migrations (Quinn and Brodeur, 1991; Chapman et al., 2012a; Chapman et al., 2012b). Such variation (e.g., partial and differential migration) can affect the population's stability through alterations in exposure to predators, fisheries, and contaminants (Kerr et al., 2010; Gahagan et al., 2015). Consequently, a full understanding of variation in movement patterns is important for management of these populations, such as conservation planning and the measurement of survival.

Among fishes, salmonids show a particularly wide variety of migration patterns (Jonsson and Jonsson, 1993; Klemetsen et al., 2003; Quinn and Myers, 2004). These patterns have been studied extensively owing to the importance of salmonids in commercial and recreational fisheries, ecosystem function, and biodiversity (NRC, 1996). Many studies have investigated the ecological and evolutionary basis of anadromy and nonanadromy (Wood and Foote, 1996; Dodson et al., 2013; Kendall et al., 2015) but there is also great variation in the extent of migration among anadromous individuals, especially for Chinook salmon (Oncorhynchus tshawytscha). The tendency to use different marine environments (coastal and open ocean) varies markedly among populations, as does the tendency to migrate northward or southward along the coast of North America (Myers et al., 1998; Trudel et al., 2009; Weitkamp, 2010; Sharma and Quinn, 2012). In addition, some individuals do not migrate into the North Pacific Ocean but rather spend all or most of their 
marine period within protected waters of southeastern Alaska (Orsi and Jaenicke, 1996) and British Columbia (Healey and Groot, 1987). It has also been known for decades that some Chinook salmon, termed "residents," are found throughout the year within Puget Sound, the Strait of Georgia, and associated inlets (Pressey ${ }^{1}$; Haw et al. ${ }^{2}$; Buckley, 1969). It has been unclear to what extent these salmon move within the inland marine waters, collectively known as the Salish Sea, and whether they leave for the coast at some point. Brannon and Setter (1989) inferred from coded wire tagging data that both maturing and immature Chinook salmon may make annual "loop" migrations from Puget Sound north into the Strait of Georgia in spring and summer and then back south into Puget Sound. However, there is no direct evidence of individual fish making such migrations.

Resident salmon seem to constitute a persistent and substantial fraction of the entire Puget Sound population of Chinook salmon. Analysis of coded-wire tag data indicated that an estimated $29 \%$ of hatchery Chinook salmon subyearlings and $45 \%$ of yearlings entering Puget Sound remained as residents (O'Neill and West, 2009). Subsequent analyses based on similar data but reflecting a different analytical approach also revealed that many Puget Sound Chinook salmon adopt a resident marine distribution pattern (Chamberlin et al., 2011). This pattern occurs but is less common with coho salmon (O. kisutch; Rohde et al., 2014). However, because coded wire tags document only the location where fish are captured, and not movement patterns, movements of individual fish cannot be determined with these tags. Research using hydroacoustic transmitters revealed differences between coho and Chinook salmon depth distributions and diel vertical migrations but did not provide information on movement throughout the basins in Puget Sound and the Salish Sea (Smith et al., 2015). Four Chinook salmon distribution patterns were observed in the Salish Sea (Arostegui et al., 2017), but information on resident Chinook salmon movements in the main basins of Puget Sound is still very limited.

The Chinook salmon evolutionarily significant unit in Puget Sound is listed as threatened under the U.S. Endangered Species Act (Federal Register, 2005). A better understanding of the movements of these fish between Puget Sound and the coastal ocean, and within Puget Sound, will help to identify patterns in habitat use, to evaluate fishery management objectives across jurisdictional boundaries, and even help to determine pathways to contaminant exposure. Resident Chinook salmon, for example, have higher accumulations of polychlorinated biphenyls (PCBs) than

\footnotetext{
1 Pressey, R. T. 1953. The sport fishery for salmon on Puget Sound. Wash. Dep. Fish., Fish. Res. Pap. 1:33-48.

${ }^{2}$ Haw, F., H. O. Wendler, and G. Deschamps. 1967. Development of Washington State salmon sport fishery through 1964. Wash. Dep. Fish., Res. Bull. 7, 192 p. [Available from website.]
}

conspecifics that migrate to the coastal ocean (O'Neill and West, 2009). As a prey item these salmon contain high enough levels of persistent organic pollutants to have possible health effects on ESA-listed killer whales (Hickie et al., 2007; Cullon et al., 2009) and to require human health advisories $\left(\mathrm{WDOH}^{3}\right)$.

In this study, individual Chinook salmon were implanted with hydroacoustic tags at a time after the majority of salmon had typically left Puget Sound for ocean feeding grounds (Healey, 1991). The detections of these presumably resident Chinook salmon were used to determine: 1) whether these individuals remained within Puget Sound, and 2) whether origin (wild or hatchery), body size, or season of tagging influenced their tendency to remain in Puget Sound. For the fish that stayed as residents within Puget Sound, we also determined 3) whether resident salmon remained in the same region where they were tagged or moved throughout Puget Sound and parts of the Salish Sea, and 4) whether detections depended on the receiver location's water depth and proximity to shore.

Finally, we compared the location features of receivers that recorded Chinook salmon with those features that were recorded with receivers that detected coho salmon collected and tagged at the same locations and times (Rohde et al., 2013). Coho and Chinook salmon in Puget Sound are ecologically similar and both exhibit partial migration (i.e., residency). The factors affecting residency, inferred from coded wire tagging data, were similar for the 2 species (Chamberlin et al., 2011; Rohde et al., 2014), and both species tended to be caught as residents in the natal basin where they entered Puget Sound. We therefore combined data from this study and that by Rohde et al. (2013) to compare directly the movement patterns of individual residents of these species in Puget Sound.

\section{Materials and methods}

\section{Tagging}

On 9 dates in June (2006 and 2007), November (2006), and December (2006, 2007, and 2008), 87 Chinook salmon were caught with a commercial purse seine in central Puget Sound (tagging area, Fig. 1). On the basis of the dates, locations, and sizes (range: 208-370 $\mathrm{mm}$ in fork length) of these salmon, all were assumed to be residents at the time of capture. To determine residency we presumed that fish of this size would have entered salt water as smolts the previous spring or summer and were still in Puget Sound about a year later at a time when migratory individuals would be moving along the coast or in offshore waters of the North Pacific Ocean (Trudel et al., 2009).

\footnotetext{
${ }^{3} \mathrm{WDOH}$ (Washington State Department of Health). 2006. Human health evaluation of contaminants in Puget Sound fish, 136 p. Div. Environ. Health, Wash. State Dep. Health, Olympia, WA. [Available from webiste.]
} 


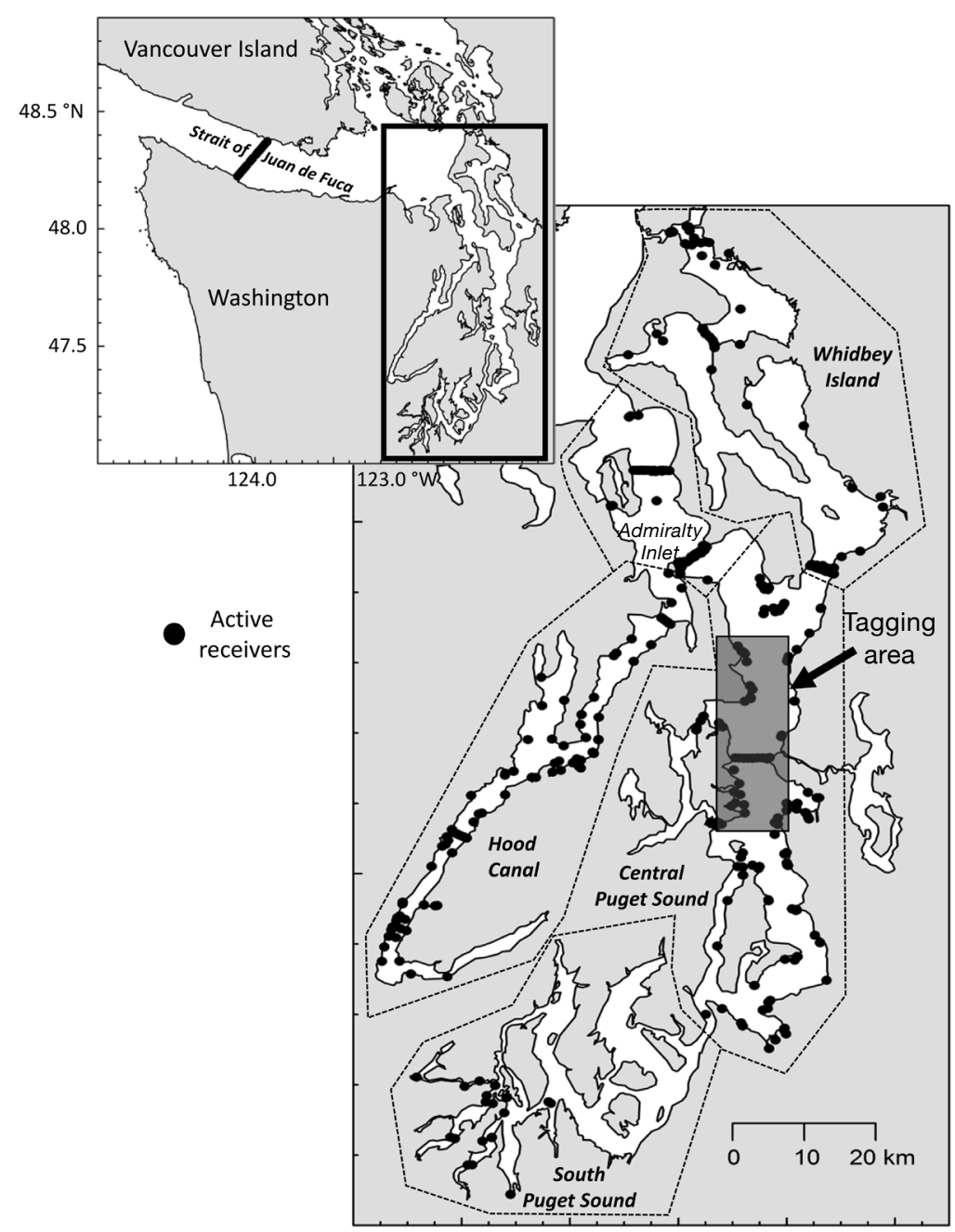

Figure 1

Map of the study area showing the locations in Puget Sound, Washington, where Chinook salmon (Oncorhynchus tshawytscha) were caught and tagged (shaded rectanglar area) during 2006-2008 and the locations of active stationary receivers. The major basins in Puget Sound are outlined by dotted lines.

Study fish were transferred from the seine into a live well with aerated flowthrough seawater at ambient temperature $\left(10-12^{\circ} \mathrm{C}\right)$ and salinity. Compressed air was pumped into the tank and dissolved oxygen levels were periodically checked. Fish with visible distress or with scale losses greater than $10 \%$ were excluded from being tagged. Weights (measured in grams) and lengths (measured in millimeters) were recorded for selected animals before tagging. Fish were transferred to a small cooler with $65 \mathrm{mg} / \mathrm{L}$ tricaine methanesulfonate and anesthetized to a point that induced loss of equilibrium but still allowed opercular movement. Each fish was checked for an adipose fin clip and codedwire tag, either of which would indicate hatchery origin. The fish was then transferred to a surgical table of closedcell foam shaped to allow the fish to be positioned on its dorsum. A supply of water infused with anesthetia was fed by gravity through a tube and delivered to the gills.

An individually coded V9 (i.e., one of the following: V9-1L at $24 \mathrm{~mm}$, V9-2L at $29 \mathrm{~mm}$, and V9-6L at $21 \mathrm{~mm}$ in length) acoustic transmitter (VEMCO, ${ }^{4}$ Bedford, Nova Scotia, Canada) was inserted into the peritoneal cavity through a small incision (15-20 mm) just off center of the linea alba of the abdomen and anterior to the pelvic fins. Tag-to-body-weight ratio did not exceed $2 \%$, well below that recommended by Hall et al. (2009) to minimize tag effects. All tags had a power output of $145 \mathrm{~dB}$, a variable ping rate, and a projected battery life of 79-537 d. The incision was closed by using absorbable surgical thread (coated Vicryl 60; Ethicon, Somerville, NJ) and sutured with a tapered RB-1 needle and using 2 surgeon knots. Including time under anesthesia, each fish was handled for an average of $6 \mathrm{~min}$ of which the surgery took approximately $2 \mathrm{~min}$. After surgery the fish were placed in a recovery tank until they were upright and swimming independently (ca. $15 \mathrm{~min}$ ); they were then released near the capture site.

\section{Data collection}

Since 2004, hydroacoustic tags have been extensively used in Puget Sound, the Strait of Georgia, and nearby water bodies to study movements of many fish species (Melnychuk et al., 2007; Welch et al., 2009; Moore et al., 2010; Hayes et al., 2011; Andrews and Quinn, 2012). Receivers were deployed in Puget Sound and maintained by several investigative teams (Hood Canal=119 receivers, Admiralty Inlet=61, central Puget Sound=271, Whidbey Basin=140 and south Puget Sound=50; Fig. 1). These studies also coincided with the Pacific Ocean Shelf Tracking Project, an international monitoring effort using the same technology to deploy arrays of receivers along the continental shelf from California to Alaska. Combined, these individual and arrayed receivers provided the means to detect fish migrating to the Pacific Ocean via the Strait of Juan de Fuca and Johnstone Strait, British Columbia, Canada, as well as fish moving within the San Juan Islands (Fig. 1; Arostegui et al., 2017). Combined, there were over 800 active receivers within the Salish Sea and an additional 55 along the Washington State coast (including the Willapa Bay subarray; Reichisky et al., 2013) in the Pacific Ocean during the study. The amount of

\footnotetext{
${ }^{4}$ Mention of trade names or commercial companies is for identification purposes only and does not imply endorsement by the National Marine Fisheries Service, NOAA.
} 
time that each receiver was active varied from a few months to years (median: $155 \mathrm{~d}$ ) according to the primary focus of the study for which they were deployed (detailed receiver location and status information are available from the Ocean Tracking Network website and Hydraphone Data Repository website). The number of receivers deployed in each basin varied through time but was always more than would be feasible for any single study.

\section{Data analysis}

Fish last detected crossing uninterrupted receiver arrays in Admiralty Inlet, the Strait of Juan de Fuca, or Johnstone Strait, or detected on individual receivers along the Washington State coast without exiting detections, were classified as transients because these detections indicated that they left Puget Sound. In contrast, fish last detected within Puget Sound (Whidbey Basin, Admiralty Inlet, Hood Canal, central or southern Puget Sound) and having no coastal or Strait of Georgia detections were classified as residents. Based on acoustic detections, the minimum amount of time it took a tagged fish to leave central Puget Sound and reach the Strait of Juan de Fuca was $6 \mathrm{~d}$. Consequently, we excluded from analysis any fish with final receiver detections within 6 days of tagging because the tracking duration was not sufficient to detect a departure. Given the distribution of receivers (Fig. 1), our probability of detecting a fish exiting the study area for coastal waters was high, but detection of an individual remaining in Puget Sound depended upon the movements and location of that fish. A Welch's $t$-test was used to determine whether fork length differed between fish that were included and excluded from the analysis. A chi-square test was used to determine whether there was a difference in proportion of wild vs. hatchery fish for fish included and excluded from the analysis. A chisquare test was employed to determine whether remaining a resident was independent of origin (hatchery or wild) or month of tagging. Welch's $t$ tests were used to evaluate whether fork length or condition index (Anderson and Neumann, 1996) had any influence on whether or not fish remained a resident within Puget Sound. Linear regression analysis allowed us to determine whether the total detection time for fish that remained in Puget Sound was influenced by fork length of the fish. We also calculated the total distance fish moved per number of days with obtained detections, and we used a Welch's $t$ test to determine whether the total distance traveled per day was different for fish that remained as residents and those that left Puget Sound.

To investigate the use of different areas of Puget Sound by Chinook salmon that remained resident (excluding transient fish), a "site-use rank sum metric" was calculated as a composite variable for each stationary receiver. This variable was created by using 4 metrics similar to those used by Rohde et al. (2013):
1) number of unique fish detected at each receiver, 2) number of days that a receiver detected at least 1 fish, 3) total amount of time spent at each receiver by all fish, divided by the number of individuals detected there (i.e., average time spent per detected fish), and 4) total number of visits to each receiver, divided by the number of individuals detected there. These 4 metrics were combined by summing the rank scores of each variable for each receiver. Low values of the site-use rank sum metric corresponded with low values of the 4 variables and high values of the metric corresponded with high values of the 4 variables. The amount of time spent by each fish at each receiver was calculated as the time between the first and last detections. If a fish was not detected for more than $1 \mathrm{~h}$ or the fish visited another receiver the duration period was terminated. A minimum of 2 detections within $1 \mathrm{~h}$ were needed to create a duration period.

To characterize areas where fish spent time, the maximum depth within the listening distance (a 520$m$ radius - an estimate of receiver range based on favorable environmental conditions and the tag output and settings) and the distance to shore were determined for each receiver (Smith et al., 2015). Receivers were then categorized as onshore-shallow $(<1$ $\mathrm{km}$ from shore and $<95 \mathrm{~m}$ deep), onshore-deep $(<1$ $\mathrm{km}$ from shore and $>95 \mathrm{~m}$ deep), or offshore-deep $(>1$ $\mathrm{km}$ from shore and $>95 \mathrm{~m}$ deep). These categories were chosen because there was a clear break between the data at these cutoffs; no receivers were located offshore in shallow water (Fig. 2).

To determine whether site use (measured as the site-use rank sum metric) differed among receiver types (onshore-shallow, onshore-deep, offshore-deep), an analysis of variance (ANOVA) was used. Univariate normality of the residuals was examined with a quantile-quantile plot, homogeneity of variances was examined by plotting standardized residuals against fitted values, and independence was examined by plotting the residuals by each factor of receiver type. A post-hoc Tukey's honestly significant difference (HSD) multiple comparison test was used to determine which receiver types were significantly different.

Diel patterns of receiver recordings of fish that remained as residents were examined by determining the number of discrete movements and presence of fish during each hour of the day. Following Chamberlin et al. (2011), we defined movements as discrete detections between individual receivers. These movement data were summarized by receiver type (offshore-deep, onshore-deep, and onshore-shallow) and tested for circular uniformity among hours by using Rayleigh tests with $\mathrm{R}$ package circular, vers. 0.4-7 (Agostinelli and Lund, 2013).

Additionally, the movements of individually tagged Chinook salmon were compared with those of tagged coho salmon (Rohde et al., 2013) by categorizing receivers as detecting 1) both Chinook and coho salmon, 2) only Chinook salmon, or 3) only coho salmon. We examined whether the proportion of fish among these 


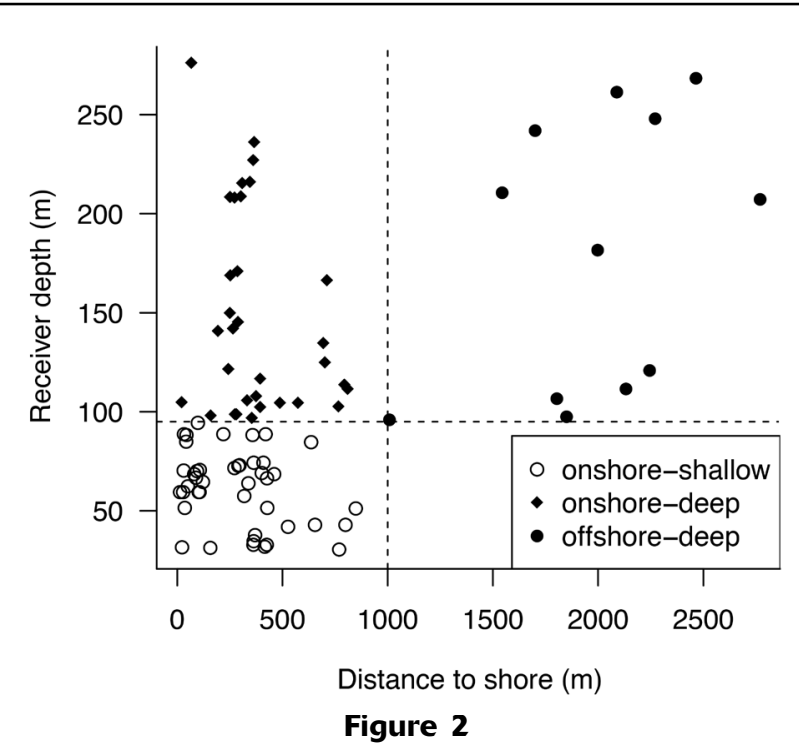

Scatterplot showing by depth (m) and distance to shore (m) the distribution of receivers used to track Chinook salmon (Oncorhynchus tshawytscha) in Puget Sound, Washington. The 3 categories used to group receivers were onshore-shallow (white circles; $<1 \mathrm{~km}$ from shore and $<95 \mathrm{~m}$ deep), onshore-deep (black diamonds; $<1 \mathrm{~km}$ from shore and $>95 \mathrm{~m}$ deep), and offshore-deep (black circles; $>1 \mathrm{~km}$ from shore and $>95 \mathrm{~m}$ deep).

categories differed by receiver type across all basins by using a chi-square test. Spearman's rank correlation analysis was used to determine whether the number of individual Chinook salmon detected correlated with the number of individual coho salmon detected at receivers that detected both species. Similarly, Spearman's rank correlation analysis was used to compare the number of days Chinook and coho salmon were detected. All data analyses were performed in $R$, vers. 3.2.1 ( $R$ Core Team, 2015).

\section{Results}

Of the 87 fish tagged, 50 were excluded, having final detections less than $6 \mathrm{~d}$ after tagging (the minimum time it took fish to reach the Strait of Juan de Fuca), a period insufficient to detect departure. Given the expansive area not covered by receivers we do not presume to provide natural or tag-related mortality for these fish, but the lack of a prolonged detection history precluded us from categorizing them as transient or resident. The 37 fish included in the analysis (for which we had detections more than 6 days after tagging) had longer fork lengths (FLs) than the excluded fish (mean: 273 vs $245 \mathrm{~mm} \mathrm{FL}, t=-3.60, P<0.01$ ). The proportions of natural and hatchery origin individuals did not differ for included fish (11 of 37 wild; 30\%) and excluded fish (16 of 50 wild, $32 \%)\left(\chi^{2}<0.01, \mathrm{df}=1\right.$, $P=1.00)$.

\section{Movement from Puget Sound}

The 37 fish analyzed were considered resident at the time of tagging, but $11(30 \%)$ subsequently left Puget Sound and were reclassified as transients, and 26 remained as residents. Eleven of the 37 were of natural origin and 26 were of hatchery origin. The origins of the transients (27\% natural) and residents (31\% natural) did not differ $\left(\chi^{2}<0.01, \mathrm{df}=1, P=1.00\right)$. Transients were detected in Puget Sound for as little as $1 \mathrm{~d}$ to as much as $124 \mathrm{~d}$ before exiting. There were too few individual departures for rigorous statistical analyses, but departures occurred throughout the year (January $=1$, April=2, June=3, July=2, November=2, December $=1$ ).

The time of year when fish were tagged did not affect the likelihood of a fish staying as a resident. Of the 37 fish included in analyses, 16 of 20 (80\%) fish tagged in June (summer) remained resident in Puget Sound, and 10 of $17(59 \%)$ tagged in the fall through November-December $\left(\chi^{2}=1.09, \mathrm{df}=1, P=0.30\right)$. Fish that remained resident and those that left Puget Sound did not differ in fork length (mean: 278 vs. $262 \mathrm{~mm}$, $t=0.99, P=0.34$ ) or condition factor (mean: 1.21 vs. 1.23 , $t=-0.57, P=0.58)$. The total duration of detection for fish that stayed as residents within Puget Sound was not significantly influenced by fish length (coefficient of determination $\left.\left[r^{2}\right]=0.12, P=0.08\right)$.

\section{Movement among basins}

Detection data indicated that fish remaining as residents seldom moved between basins. Twenty-six fish remained residents: 10 individuals (fish 1-10, Fig. 3) were never detected outside central Puget Sound; 9 individuals moved only between Admiralty Inlet and central Puget Sound (fish 11-19, Fig. 3); 6 individuals moved between central Puget Sound, Admiralty Inlet, and the Whidbey Basin (fish 20-25, Fig. 3); and 1 fish moved between central Puget Sound, Admiralty Inlet, and Hood Canal (fish 26, Fig. 3). The 11 fish that left Puget Sound had different movement patterns (fish 27-37, Fig. 3). The last known locations varied for waters within Lime Kiln State Park on San Jun Island (fish 27-28, Fig. 3; Arostegui et al. 2017), the Strait of Juan de Fuca (fish 29-31, 33-35, 37, Fig. 3), waters off northwestern Vancouver Island near Lippy Point (Rechisky et al., 2013; fish 32, Fig. 3), and the Washington State coast at Willapa Bay (fish 36, Fig. 3). Interestingly, these fish were not detected on the Canadian Northern Strait of Georgia or Queen Charlotte subarrays. Hood Canal had 119 receivers active during at least part of the study period but only 2 individuals (fish 26 and 30, Fig. 3) were detected there. Similarly, south Puget Sound had 50 active receivers and only 1 fish was detected there (fish 27, Fig. 3).

\section{Movement within Puget Sound}

The site-use rank sum metric was used to measure fish use within Puget Sound. Fish that remained within 


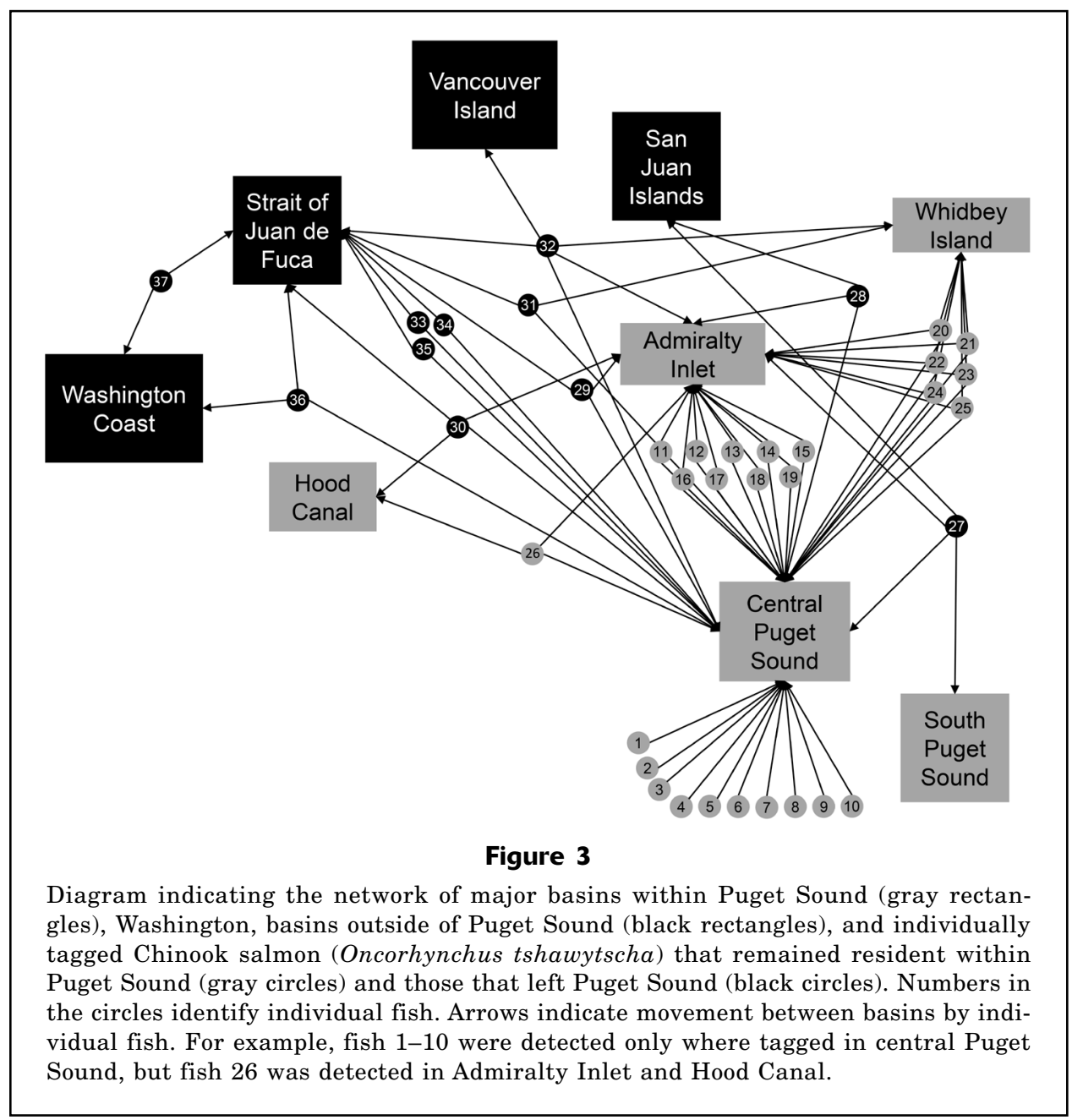

Puget Sound used offshore-deep, onshore-deep sites and onshore-shallow sites differently (ANOVA: $F_{2,51}=4.11$, $P=0.02$ ). A Tukey's HSD post-hoc multiple comparison test indicated that site use was greater at offshore-deep sites (mean: 120.27) and onshore-deep sites (mean: 126.67) than at onshore-shallow sites (mean: 85.17).

Fish presence at receivers showed a $24 \mathrm{~h}$ periodicity only at onshore-shallow receiver locations (mean: 08:40 h, $z=0.12, P=0.047$, Fig. 4). Offshore-deep and onshoredeep sites showed no peak in the hour of presence of tagged fish. Fish movement was distributed uniformly among hours regardless of receiver type (Fig. 4).

The total distance moved per day (an indicator of gross movement and not necessarily directionality) was farther for fish that left Puget Sound than for fish that remained as residents (mean: 6.09 vs. $2.69 \mathrm{~km} / \mathrm{d}$, $t=-2.19, P=0.05)$. For Chinook salmon within Puget Sound, the total distance moved provided only a limited picture of fish behavior, and fish showed a range of patterns. For example, one fish was tagged in central Puget Sound on 1 November 2006, detected leaving Puget Sound through the Strait of Juan de Fuca on 16 November, and detected along the coast of Wash- ington on 3 December, having moved about $280 \mathrm{~km}$ in $17 \mathrm{~d}$ or $16.5 \mathrm{~km} / \mathrm{d}$ (Fig. 5A). This fish continued along the coast west of Willapa Bay through 1 January 2007 but was detected again at the Strait of Juan de Fuca on 14 March 2007. Therefore, had it been caught, on the basis of its locations, it would have been considered a resident in November, a migrant to the coast in December, and a resident in March. In contrast, a resident fish was tagged in central Puget Sound on 7 June 2007 and then detected repeatedly over 8 months moving between 14 nearby receivers (within an extent of only $45 \mathrm{~km} \mathrm{~N}$ to $\mathrm{S}$ and $21 \mathrm{~km} \mathrm{E}$ to W; Fig. 5B). Other individuals fell within this range of movement; most were detected moving among receivers within central Puget Sound.

\section{Comparison with coho salmon movements}

To compare the behavior of Chinook and coho salmon, receivers were identified that detected the 37 Chinook salmon from this study and the 35 coho salmon reported by Rohde et al. (2013). Seventy-four receivers throughout all basins detected both species, of which 30 receivers 


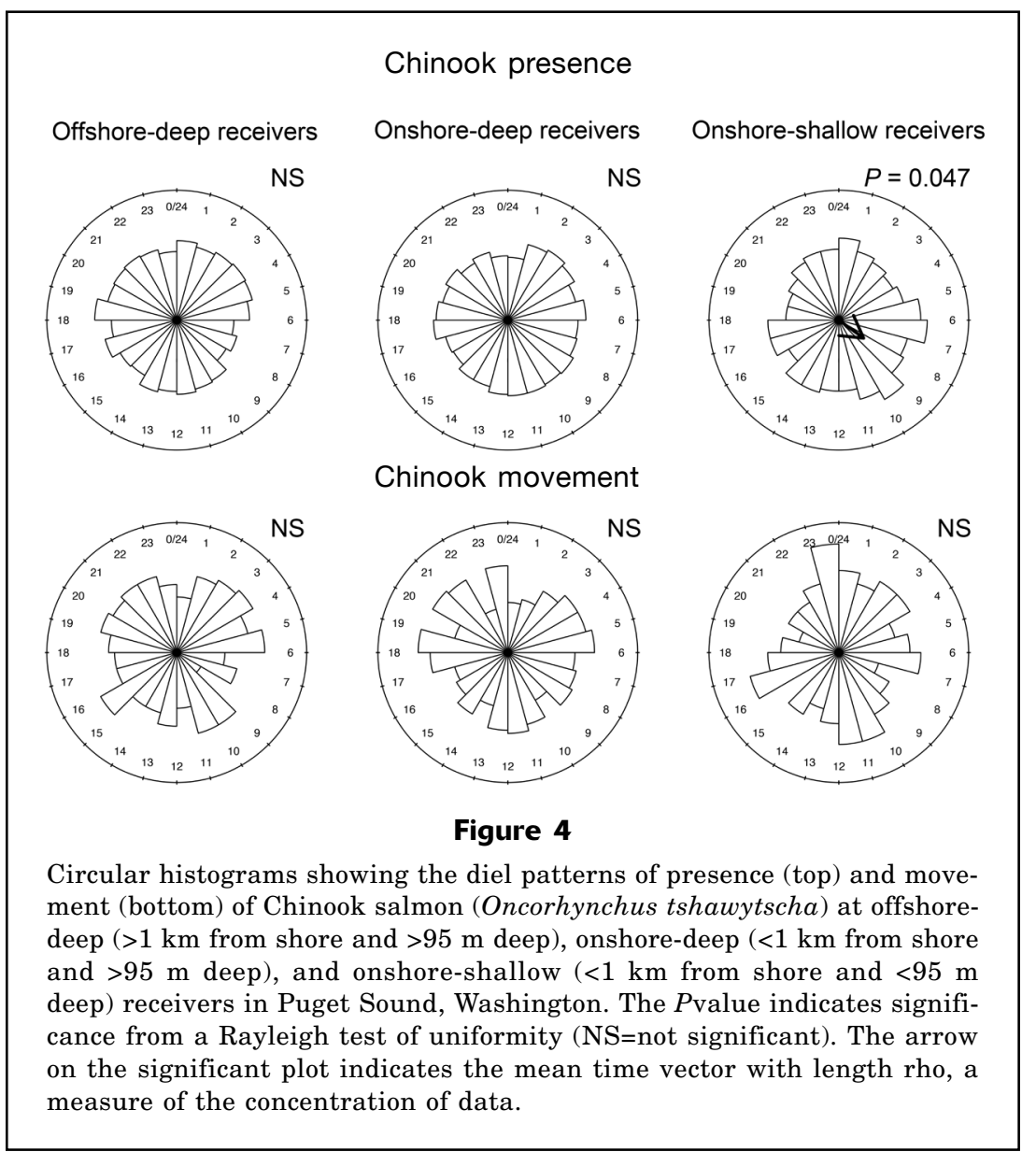

detected only Chinook salmon, and 51 receivers detected only coho salmon. Chinook salmon were detected on 104 receivers and coho salmon on 125 receivers. The species detected (both, Chinook salmon only, coho salmon only) varied with receiver type (offshore-deep, onshore-deep, onshore-shallow: $\chi^{2}=21.88, \mathrm{df}=4, P<0.01$ ). The receivers that detected only Chinook salmon were mostly onshore-shallow receivers (70\%), followed by onshoredeep receivers $(23 \%)$, and offshore-deep receivers $(7 \%)$ whereas the receivers that detected only coho salmon were mostly offshore-deep (45\%), followed by onshoreshallow (33\%), and onshore-deep (22\%). The receivers that detected both species were more evenly distributed (38\% offshore-deep, 35\% onshore-deep, and 27\% onshore-shallow). The 44 receivers within Puget Sound that detected both Chinook and coho salmon showed positive correlations with the numbers of individual fish (coefficient of correlation $[r]=0.47, P<0.01$ ) and days with detections $(r=0.54, P<0.01)$.

\section{Discussion}

All the Chinook salmon tagged in this study were categorized initially as residents because they were still in
Puget Sound late in their first or in their second year in salt water. Had all of them remained within Puget Sound, we would have inferred a clear distinction between these resident fish and the typical migrants that leave Puget Sound after a few months to feed in the coastal or open ocean waters until they return to spawn. However, 30\% of the tagged fish later left Puget Sound, and so were termed transients. If they had been caught in fisheries along the coast, there is no way to know that they had spent significant time in Puget Sound. Indeed, some fish were tracked out to the coast and then back into Puget Sound, further illustrating the flexibility of residency and coastal migrations.

There was no effect of size, origin (hatchery or wild), tagging location, or tagging season on whether a fish remained resident or became a transient, although the small sample sizes limited our effort to detect effects. For example, we included only fish with a minimum of $6 \mathrm{~d}$ of detection data (sufficient to detect possible departure). The Chinook salmon detected for more than $6 \mathrm{~d}$ after tagging were larger than those omitted for lack of ample detection data. This observation is consistent with size-selective natural mortality or an effect of handling, although 2 laboratory studies found little or no size effects on survival for Chinook salmon with 
A

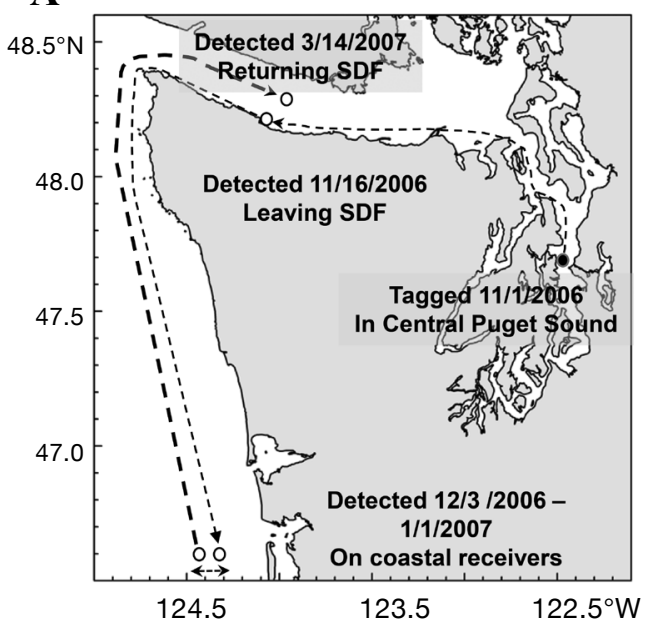

B

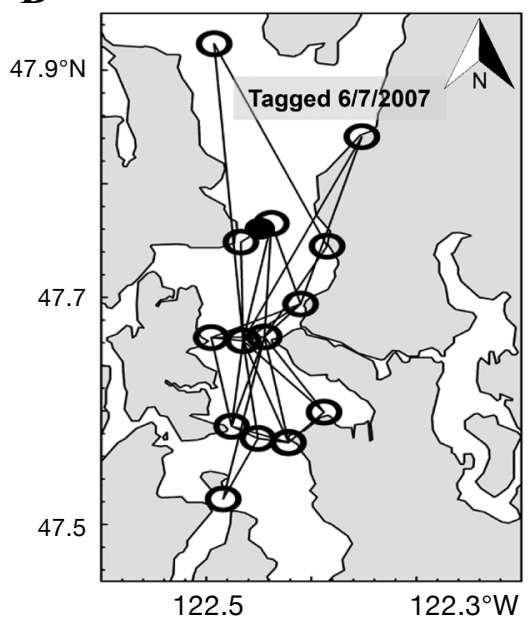

Figure 5

Examples of movement by individual Chinook salmon (Oncorhynchus tshawytscha) classified as (A) transient and (B) resident. The solid black circle in each panel indicates the tagging location, and open circles indicate receivers with that detected fish. The transient Chinook salmon (fish 37), tagged in central Puget Sound, left through the Strait of Juan de Fuca, was detected on the southern coast of Washington, and then returned to the Strait of Juan de Fuca. The resident Chinook salmon (fish 11) was tagged in central Puget Sound and detected at 14 receivers within central Puget Sound. The lines in panel B indicate movement of fish 11 between receivers.

surgically implanted acoustic tags (Hall et al., 2009; Rechisky and Welch ${ }^{5}$ ). The detected fish did not represent a different age-group and were assumed to be broadly representative of the tagged fish, however the movements and fate of the undetected fish were unknown. Interpretation of the detection data was further complicated by the uncertain origin of the individual fish, some of which may have originated outside Puget Sound. However, the transients did not leave Puget Sound synchronously, rather they departed at seemingly random times over much of the year. This variation in departure timing and the small size of fish suggests that individuals tagged that subsequently left did not do so as part of a spawning migration to rivers outside Puget Sound, but more likely as part of feeding migrations.

Chinook salmon in our study showed behavior similar to that of Puget Sound coho salmon studied similarly by Rohde et al. (2013). Of the Chinook salmon tagged and detected, 30\% were classified as transients, and of the coho salmon tagged and detected, $20 \%$ were classified as transients according to the same criteria.

\footnotetext{
${ }^{5}$ Rechisky, E. L., and D. W. Welch. 2010. Surgical implantation of acoustic tags: influence of tag loss and tag-induced mortality on free-ranging and hatchery-held spring Chinook salmon (Oncorhynchus tshawytscha) smolts. In PNAMP Special Publication: Tagging, telemetry, and marking measures for monitoring fish populations: a compendium of new and recent science for use in informing technique and decision modalities (K. S. Wolf and J. S. O'Neal, eds.), p. 69-94. PNAMP Spec. Publ. 2010-002. Pacific Northwest Aquatic Monitoring Partnership, Duvall, WA. [Available from website]
}

Both species left Puget Sound throughout the year, showing no clear modal season, and for neither species did residents and transients differ in size, wild-hatchery origin, or time of year when tagged. Moreover, indices of site use at common receiver sites (numbers of fish detected, days with detections) were significantly correlated between the two species. In addition, coho and Chinook salmon that remained in Puget Sound as residents seldom moved from the central basin where they were tagged. Receivers in south Puget Sound and Hood Canal detected only 1 and 2 tagged fish, respectively. Few detections occurred in the Whidbey Basin as well. These areas are not devoid of resident Chinook salmon (Chamberlin et al., 2011) or coho salmon (Rohde et al., 2014), but both species tend to remain in one basin unless they leave Puget Sound entirely.

There were several significant differences between the movements of the 2 salmon species. Chinook salmon were detected on fewer different receivers, suggesting less overall movement than that of coho salmon, and Chinook salmon were also detected more often than coho salmon at receivers onshore and in shallower water. In addition, Chinook salmon showed weak and inconsistent diel activity patterns. In contrast, coho salmon were most active at shallow, onshore sites at night and deep, offshore sites during the day and were most often detected onshore near dawn and offshore in the afternoon (Rohde et al., 2013). These differences are also consistent with the pronounced differences in depth distributions and diel vertical movement reported by Smith et al. (2015) for coho and Chinook salmon in Puget Sound. 
Similar to the analysis of acoustically tagged coho and Chinook salmon, analysis of coded-wire tagging data also revealed differences and similarities that shed light on the phenomenon of residency (partial migration) of salmon. Residency seems much more prevalent with Chinook salmon (O'Neill and West, 2009; Chamberlin et al., 2011) than with coho salmon (Rohde et al., 2014), although it is not possible to precisely estimate the fraction for either species that adopts this behavior. However, the proportions of subyearling and yearlings adopting resident behavior were positively correlated between the two species among years, as well correlated with environmental variables (Rohde et al., 2014), suggesting common influences on behavior. In addition, salmon of both species that remain as residents in Puget Sound tend to be caught in natal basins more often than would happen by chance, although some movement certainly occurs (Chamberlin and Quinn, 2014; Rohde et al., 2014). Taken together, the combination of tagging and tracking studies for both species indicate that commonalities exceeded differences, and that the main difference was the greater prevalence of residency and somewhat more restricted movements within Puget Sound for Chinook salmon.

A number of diadromous species also exhibit alternative migratory behaviors that include resident forms of behavior similar to those of Puget Sound coho and Chinook salmon (Chapman et al., 2012a, Chapman et al. 2012b). Striped bass (Morone saxatilis) have both resident fish that do not leave the natal river or estuary and migratory fish that travel long distances in coastal waters. Clarke (1968) referred to these fish as contingents within populations, defined as "a group of fish that engage in a common pattern of seasonal migration between feeding areas, wintering areas, and spawning areas" (p. 320). Subsequent research with otolith microchemistry has revealed 3 distinct contingents: a resident group that remains in fresh water, a mesohaline group that occupies estuarine waters, and a migratory group that uses the coastal Atlantic Ocean (Secor, 1999). White perch (M. americana) displays 2 contingents; the great majority use estuarine habitats and a small fraction reside in rivers (Kerr et al., 2009). Individual white perch adopt one pattern or the other and do not switch patterns, whereas striped bass can shift between patterns (Zlokovitz et al., 2003).

The widespread occurrence of residency in diadromous species, such as salmonids, suggests advantages for having a portion of the population not undergo extensive ocean migrations. One explanation for the phenomenon is that resident fish, compared to ocean migrants, might be exposed to fewer predators (Emmett and Schiewe, 1997). However, one consequence of residency is slower growth than that of members of the cohort feeding in the ocean, as evidenced by smaller size at age in coho salmon (Milne, 1950; Pressey ${ }^{1}$; Rohde et al., 2014) and pink salmon $\left(\right.$ Pressey $\left.^{1}\right)$, and the smaller size of resident Chinook salmon (Pressey ${ }^{1}$ ). Therefore, any hypothesis to explain residency must address this growth differential, as well as the greater prevalence of residency among Chinook than among coho salmon. Perhaps, because coho salmon tend to spend only a single winter at sea, the need to grow fast is greater than it is for Chinook salmon (Sandercock, 1991; Pearcy, 1992), which delay maturation and the corresponding return to spawn when growth is reduced (Healey, 1991).

In Puget Sound, the incidence of transients, some of which later return from the coast and resume residency in the sound, implies behavioral patterns that reflect modes along a continuum rather than discrete variants. This variability contributes to the "portfolio effect" (where diversification minimizes the risk of instability) for Chinook salmon and coho salmon, although in the face of broad regime shifts and anthropogenic effects across the entire region, it has not precluded declines in the species. The processes affecting migratory decisions, whether physiological (e.g., growth rate, lipid deposition, hormone levels) or environmental (e.g., water temperature, prey availability) remain unknown. However, the contribution of these drivers differs for coho salmon, because residency is less often displayed, compared with Chinook salmon. Regardless, although not likely accounting for a large portion of Salish Sea salmonids, partial migration and late migration strategies could justify adjustment to calculations of early marine mortality in Chinook salmon survival studies such as that of Neville et al. (2015), and the concept could be explored for other species, such as sockeye salmon (Oncorhynchus nerka) (Wood et al., 2012).

In summary, Chinook salmon display a wide range of alternative migration patterns. These patterns include those of nonanadromous males that mature as parr (Gebhards, 1960; Pearsons et al., 2009; Johnson et al., 2012), of juveniles that migrate to sea in their first or second year of life (Taylor, 1990; Healey, 1991), and of anadromous fish that remain as residents in protected marine waters $\left(\right.$ Pressey $^{1}$ ) or that migrate to the coast or the open North Pacific Ocean (Healey, 1983; Sharma and Quinn, 2012). This list should also include variants, such as those termed transients, fish initially adopting residency and then moving to the outer coast, and some that return to Puget Sound before maturation. Although the sample size and approach used in our study cannot precisely quantify the degree of prevalence of late migration and partial migration strategies, these are behaviors clearly adopted by a portion of the population as a whole.

Alternative patterns of migration, as well as the presence of nonmigratory and migratory animals, can enhance the resilience of populations (Kerr et al., 2010) because the fish experience different regimes of growth and mortality. The reduced growth of resident salmon compared with those feeding along the coast is balanced against the higher survival rates of resident fish. Survival rates of coho salmon entering the Salish Sea are higher on average than coho salmon of coastal populations but the survival rates in these regions have shown different trajectories over the past decades (Zimmerman et al., 2015). Assuming similar patterns 
with Chinook salmon, the resident component of the population complex might enjoy higher overall fitness in some regimes and lower in others, effectively buffering the complex as a whole. If so, variants in migratory patterns may contribute to the capacity of Chinook salmon to persist during periods when environmental conditions in some marine habitats are less favorable.

\section{Acknowledgments}

We appreciate K. Dobszynski, J. Chamberlin, J. Hall, and T. Sandell, among many others for aid with fieldwork and F. Goetz, Washington Department of Fish and Wildlife, the U.S. Army Corps of Engineers, Seattle Aquarium, Seattle City Light, the Nisqually and Squaxin Tribes, Beam Reach, and the Pacific Ocean Shelf Tracking Project. D. Spilsbury-Pucci, S. Moore and S. O'Neill gave invaluable input and interpretation. Partial funding for this project was provided by the State of Washington's Salmon Recovery Funding Board, National Marine Fisheries Service, and others.

\section{Literature cited}

Agostinelli, C., and U. Lund.

2013. R package 'circular': circular statistics (version 0.47). [Available from website.]

Arostegui, M. C., J. M. Smith, A. N. Kagley, D. SpilsburyPucci, K. L. Fresh, and T. P. Quinn.

2017. Spatially clustered movement patterns and segregation of subadult Chinook salmon within the Salish Sea. Mar. Coast. Fish. 9:1-12. Article

Anderson, R. O., and R. M. Neumann.

1996. Length, weight, and associated structural indices. In Fisheries Techniques, $2^{\text {nd }}$ ed. (B. R. Murphy, and D. W. Willis, eds.), p. 447-481. Am. Fish. Soc., Bethesda, MD.

Andrews, K. S., and T. P. Quinn.

2012. Combining fishing and acoustic monitoring data to evaluate the distribution and movements of spotted ratfish Hydrolagus colliei. Mar. Biol. 159:769-782. Article

Brannon, E., and A. Setter.

1989. Marine distribution of a hatchery fall Chinook salmon population. In Proceedings of the salmonid migration and distribution symposium; Trodheim, Norway, 23-25 June 1987 (E. Brannon and B. Jonsson, eds.), p. 63-69. Univ. Washington, Seattle, WA.

Buckley, R. M.

1969. Analysis of the Puget Sound sport fishery for resident coho salmon, Oncorhynchus kisutch (Walbaum). M.S. thesis, 73 p. Univ. Wash., Seattle, WA.

Chamberlin, J. W., and T. P. Quinn.

2014. Effects of natal origin on localized distributions of Chinook salmon, Oncorhynchus tshawytscha, in the marine waters of Puget Sound, Washington. Fish. Res. 153:113-122. Article

Chamberlin, J. W., T. E. Essington, J. W. Ferguson, and T. P. Quinn.

2011. The influence of hatchery rearing practices on salmon migratory behavior: Is the tendency of Chinook salmon to remain within Puget Sound affected by size and date of release? Trans. Am. Fish. Soc. 140:13981408. Article

Chapman, B. B., K. Hulthén, J. Brodersen, P. A. Nilsson, C. Skov, L.-A. Hansson, and C. Brönmark.

2012a. Partial migration in fishes: causes and consequences. J. Fish Biol. 81:456-478. Article

Chapman, B. B., C. Skov, K. Hulthén, J. Brodersen, P. A. Nilsson, L.-A. Hansson, and C. Brönmark.

2012b. Partial migration in fishes: definitions, methodologies and taxonomic distribution. J. Fish Biol. 81:479-499. Article

Clark, J.

1968. Seasonal movements of striped bass contingents of Long Island Sound and the New York Bight. Trans. Am. Fish. Soc. 97:320-343. Article

Cullon, D. L., M. B. Yunker, C. Alleyne, N. J. Dangerfield, S. O’Neill, M. J. Whiticar, and P. S. Ross.

2009. Persistent organic pollutants in Chinook salmon (Oncorhynchus tshawytscha): implications for resident killer whales of British Columbia and adjacent waters. Environ. Toxicol. Chem. 28:148-161. Article

Dodson, J. J., N. Aubin-Horth, V. Thériault, and D. J. Páez. 2013. The evolutionary ecology of alternative migratory tactics in salmonid fishes. Biol. Rev. Camb. Philos. Soc. 88:602-625. Article

Emmett, R. L., and M. H. Schiewe (eds.).

1997. Estuarine and ocean survival of northeastern Pacific salmon: proceedings of the workshop. NOAA Tech. Memo. NMFS-NWFSC-29, 313 p.

Federal Register.

2005. Endangered and threatened species: final listing determinations for 16 ESUs of West Coast salmon, and final 4(d) protective regulations for threatened salmonid ESUs. Fed. Regist. 70:37160-37204. [Available from website.]

Gahagan, B. I., D. A. Fox, and D. H. Secor.

2015. Partial migration of striped bass: revisiting the contingent hypothesis. Mar. Ecol. Prog. Ser. 525:185-197. Article

Gebhards, S. V.

1960. Biological notes on precocious male Chinook salmon parr in the Salmon River drainage, Idaho. Prog. FishCult. 22:121123.

Hall, J. E., J. Chamberlin, A. N. Kagley, C. Greene, and K. L. Fresh.

2009. Effects of gastric and surgical insertions of dummy ultrasonic transmitters on juvenile Chinook salmon in seawater. Trans. Am. Fish. Soc. 138:52-57. Article

Hayes, M. C., S. P. Rubin, R. R. Reisenbichler, F. A. Goetz, E. Jeanes, and A. McBride.

2011. Marine habitat use by anadromous bull trout from the Skagit River, Washington. Mar. Coast. Fish. 3:394410. Article

Healey, M. C.

1983. Coastwide distribution and ocean migration patterns of stream- and ocean-type Chinook salmon, Oncorhynchus tshawytscha. Can. Field-Nat. 97:427-433.

1991. Life history of Chinook salmon (Oncorhynchus tshawytscha). In Pacific salmon life histories (C. Groot and L. Margolis, eds.), p. 311-393. UBritishC Press, Vancouver, Canada.

Healey, M. C., and C. Groot.

1987. Marine migration and orientation of oceantype Chinook and sockeye salmon. Am. Fish. Soc. Symp. 1:298-312. 
Hickie, B. E., P. S. Ross, R. W. MacDonald, and J. K. B. Ford. 2007. Killer whales (Orcinus orca) face protracted health risks associated with lifetime exposure to PCBs. Environ. Sci. Technol. 41:6613-6619. Article

Johnson, J., T. Johnson, and T. Copeland.

2012. Defining life histories of precocious male parr, minijack, and jack Chinook salmon using scale patterns. Trans. Am. Fish. Soc. 141:1545-1556. Article

Jonsson, B., and N. Jonsson.

1993. Partial migration: niche shift versus sexual maturation in fishes. Rev. Fish Biol. Fish. 3:348-365. Article

Kendall, N. W., J. R. McMillan, M. R. Sloat, T. W. Buehrens, T. P. Quinn, G. R. Pess, K. V. Kuzishchin, M. M. McClure, and R. W. Zabel.

2015. Anadromy and residency in steelhead and rainbow trout (Oncorhynchus mykiss): a review of the processes and patterns. Can. J. Fish. Aquat. Sci. 72:319-342. Article

Kerr, L. A., D. H. Secor, and P. M. Piccoli.

2009. Partial migration of fishes as exemplified by the estuarine-dependent white perch. Fisheries 34:114-123.

Kerr, L. A., S. X. Cadrin, and D. H. Secor.

2010. The role of spatial dynamics in the stability, resilience, and productivity of an estuarine fish population. Ecol. Appl. 20:497-507. Article

Klemetsen, A., P.-A. Amundsen, J. B. Dempson, B. Jonsson, N. Jonsson, M. F. O'Connell, and E. Mortensen.

2003. Atlantic salmon Salmo salar L., brown trout Salmo trutta L. and Arctic charr Salvelinus alpinus (L.): a review of aspects of their life histories. Ecol. Freshw. Fish. 12:1-59. Article

Lucas, M. C., and E. Baras.

2001. Migration of freshwater fishes, 440 p. Blackwell Science, Ltd., Oxford, UK.

Melnychuk, M. C., D. W. Welch, C. J. Walters, and V. Christensen.

2007. Riverine and early ocean migration and mortality patterns of juvenile steelhead trout (Oncorhynchus mykiss) from the Cheakamus River, British Columbia. Hydrobiologia 582:55-65.

Milne, D. J.

1950. The difference in the growth rate of coho salmon on the east and west coasts of Vancouver Island in 1950. Fish. Res. Board Can., Prog. Rep. Pacific Coast Stn. 85:80-82.

Moore, M. E., B. A. Berejikian, and E. P. Tezak.

2010. Early marine survival and behavior of steelhead smolts through Hood Canal and the Strait of Juan de Fuca. Trans. Am. Fish. Soc. 139:49-61. Article

Myers, J. M., R. G. Kope, G. J. Bryant, D. Teel, L. J. Lierheimer, T. C. Wainwright, W. S. Grant, F. W. Waknitz, K. Neely, S. T. Lindley, and R. S. Waples.

1998. Status review of Chinook salmon from Washington, Idaho, Oregon, and California. NOAA Tech. Memo. NMFSNWFSC35, $443 \mathrm{p}$.

Neville, C. M., R. J. Beamish, and C. M. Chittenden.

2015. Poor survival of acoustically-tagged juvenile Chinook salmon in the Strait of Georgia, British Columbia, Canada. Trans. Am. Fish. Soc. 141:25-33. Article

NRC (National Research Council).

1996. Upstream: salmon and society in the Pacific Northwest, 452 p. The National Academies Press, Washington, DC.

O'Neill, S. M., and J. E. West.

2009. Marine distribution, life history traits, and the accumulation of polychlorinated biphenyls in Chinook salmon from Puget Sound, Washington. Trans. Am. Fish. Soc. 138:616-632. Article

Orsi, J. A., and H. W. Jaenicke.

1996. Marine distribution and origin of prerecruit Chinook salmon, Oncorhynchus tshawytscha, in southeastern Alaska. Fish. Bull. 94:482-497.

Pearcy, W. G.

1992. Ocean ecology of North Pacific salmonids, 179 p. Univ. Wash. Press, Seattle, WA.

Pearsons, T. N., C. L. Johnson, B. B. James, and G. M. Temple. 2009. Abundance and distribution of precociously mature male spring Chinook salmon of hatchery and natural origin in the Yakima River. North Am. J. Fish. Manage. 29:778-790. Article

Quinn, T. P., and R. D. Brodeur.

1991. Intraspecific variations in the movement patterns of marine animals. Am. Zool. 31:231-241.

Quinn, T. P., and K. W. Myers.

2004. Anadromy and the marine migrations of Pacific salmon and trout: Rounsefell revisited. Rev. Fish Biol. Fish. 14:421-442. Article

$\mathrm{R}$ Core Team.

2015. R: a language and environment for statistical computing. R Foundation for Statistical Computing, Vienna, Austria. [Available from website, accessed June 2015].

Rechisky, E. L., D. W. Welch, A. D. Porter, M. C. Jacobs-Scott, and P. M. Winchell.

2013. Influence of multiple dam passage on survival of juvenile Chinook salmon in the Columbia River estuary and coastal ocean. Proc. Nat. Acad. Sci. USA 110:6883-6888. Article

Rohde, J., A. N. Kagley, K. L. Fresh, F. A. Goetz, and T. P. Quinn.

2013. Partial migration and diel movement patterns in Puget Sound coho salmon. Trans. Am. Fish. Soc. 142:16151628. Article

Rohde, J., K. L. Fresh, and T. P. Quinn.

2014. Factors affecting partial migration in Puget Sound coho salmon. North Am. J. Fish. Manage. 34:559-570. Article

Sandercock, F. K.

1991. Life history of coho salmon (Oncorhynchus kisutch). In Pacific salmon life histories (C. Groot and L. Margolis, eds.), p. 395-445. Univ. British Columbia Press, Vancouver, Canada.

Secor, D. H.

1999. Specifying divergent migrations in the concept of stock: the contingent hypothesis. Fish. Res. 43:13-34. Article

2015. Migration ecology of marine fishes, 304 p. Johns Hopkins Univ. Press, Baltimore, MD.

Sharma, R., and T. P. Quinn.

2012. Linkages between life history type and migration pathways in freshwater and marine environments for Chinook salmon, Oncorhynchus tshawytscha. Acta Oecol. 41:1-13. Article

Smith, J. M., K. L. Fresh, A. N. Kagley, and T. P. Quinn.

2015. Ultrasonic telemetry reveals seasonal variation in depth distribution and diel vertical migrations of subadult Chinook and coho salmon in Puget Sound. Mar. Ecol. Prog. Ser. 532:227-242. Article 
Taylor, E. B.

1990. Environmental correlates of life-history variation in juvenile Chinook salmon, Oncorhynchus tshawytscha (Walbaum). J. Fish Biol. 37:1-17. Article

Trudel, M., J. Fisher, J. A. Orsi, J. F. T. Morris, M. E. Thiess, R. M. Sweeting, S. Hinton, E. A. Fergusson, and D. W. Welch.

2009. Distribution and migration of juvenile Chinook salmon derived from coded wire tag recoveries along the continental shelf of western North America. Trans. Am. Fish. Soc. 138:1369-1391. Article

Weitkamp, L. A.

2010. Marine distributions of Chinook salmon from the west coast of North America determined by coded wire tag recoveries. Trans. Am. Fish. Soc. 139:147-170. Article

Welch, D. W., M. C. Melnychuk, E. R. Rechisky, A. D. Porter, M. C. Jacobs, A. Ladouceur, R. S. McKinley, and G. D. Jackson.

2009. Freshwater and marine migration and survival of endangered Cultus Lake sockeye salmon (Oncorhyn- chus nerka) smolts using POST, a large-scale acoustic telemetry array. Can. J. Fish. Aquat. Sci. 66:736-750. Article

Wood, C. C., and C. J. Foote.

1996. Evidence for sympatric genetic divergence of anadromous and nonanadromous morphs of sockeye salmon (Oncorhynchus nerka). Evolution 50:1265-1279. Article

Wood, C. C., D. W. Welch, L. Godbout, and J. Cameron.

2012. Marine migratory behavior of hatchery-reared anadromous and wild non-anadromous sockeye salmon revealed by acoustic tags. Am. Fish. Soc. Symp. 76:289-311.

Zimmerman, M. S., J. R. Irvine, M. O'Neill, J. H. Anderson, C. M. Greene, J. Weinheimer, M. Trudel, and K. Rawson.

2015. Spatial and temporal patterns in smolt survival of wild and hatchery coho salmon in the Salish Sea. Mar. Coast. Fish. 7:116-134. Article

Zlokovitz, E. R., D. H. Secor, and P. M. Piccoli.

2003. Patterns of migration in Hudson River striped bass as determined by otolith microchemistry. Fish. Res. 63:245259. Article 